\title{
Effects of Endurance Training and Adenosine on the Expression of the A2B Gene on the Isch- emic-Reperfusion Model of the Male Rat Brain
}

\section{Mansur Rahimi, Farah Nameni*}

Department of physical education, Varamin Pishva Branch, Islamic Azad University, Varamin, Iran

\section{A BSTR A CT}

Introduction: Stroke is one of the most prevalent causes of death worldwide. Strategies that increase the resistance of neural cells to ischemia-induced damages are crucial to prevent brain damage. This study aimed to investigate the effect of endurance training and adenosine injection on the expression of the $\mathrm{A} 2 \mathrm{~B}$ gene after ischemia-reperfusion in Wistar rats. Materials and Methods: 40 male Wistar rats $(220 \pm 20 \mathrm{~g})$ were divided into four groups; endurance training +adenosine + ischemia, ischemia + adenosine, endurance training + ischemia, and control. Ischemic induction was conducted through the common carotid artery ligation. After the ischemic insult, an endurance training protocol was performed. Eight weeks after ischemic induction and exercise protocol, blood samples were taken from rats, and expression of the A2B gene was measured. Results: There was a significant difference in the expression of the A2B gene between the ischemic control and endurance training +adenosine+ ischemia groups. Conclusion: It seems endurance training protocol protected neurons from ischemic injury and improved rat brain function. The administration of adenosine has also played an important role in the regulatory mechanisms of ischemic-reperfusi

*Corresponding Author: Farah Nameni

E-mail: dastavard96@gmail.com 


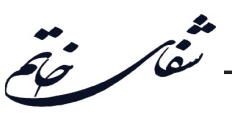

تاثير تمرين استقامتى و آدنوزين بر بيان زن A2B مدل ايسكمى - رييرفيوزن مغز موش صحرايى نر

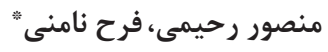

كروه تربيتبدنى، واحد ورامين يِيشوا، دانشخاه آزاد اسلامى، ورامين، ايران

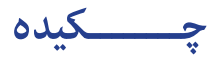

مقدمه: سكتهٔ مغزى از شايعترين علل مرك و مير در جهان است. لذا راهكارهايى كه موجب إنب افزايش

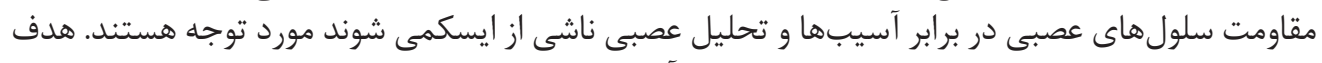

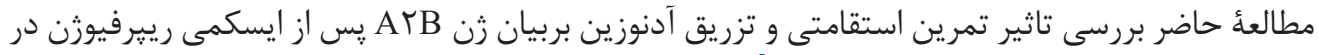

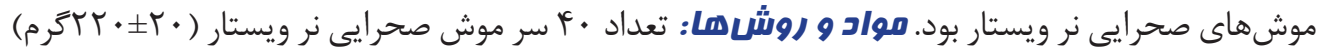

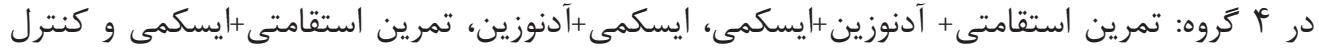

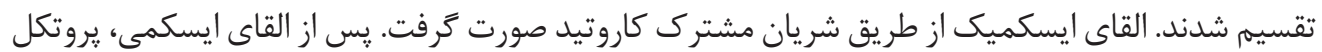

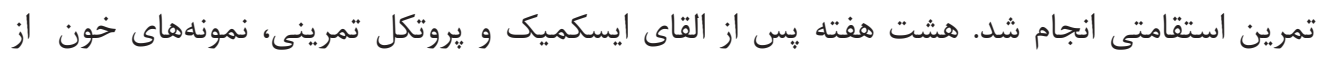

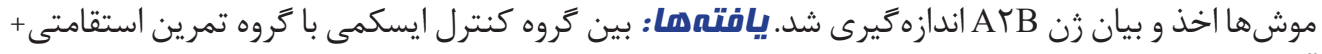

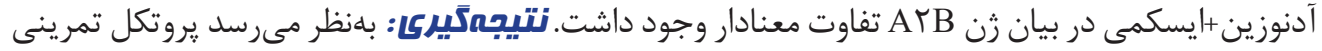

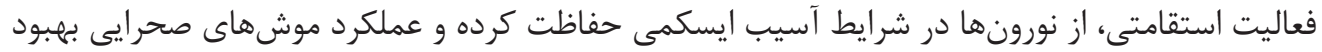

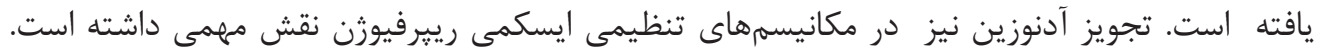

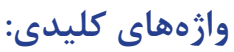

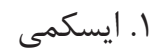

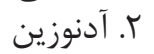

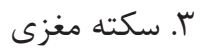

*ونويسنده مسئول: فرح نامنى

يست الكترونيك: dastavard96@gmail.com 


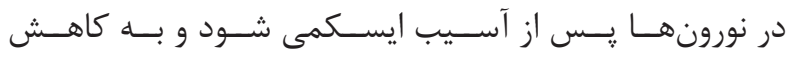

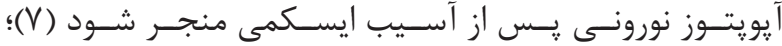

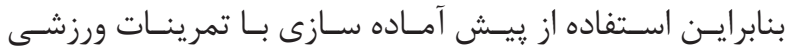

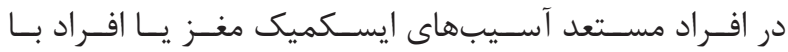

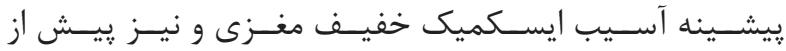

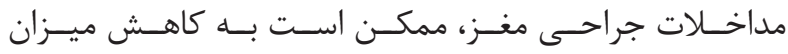

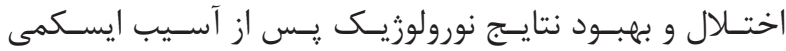

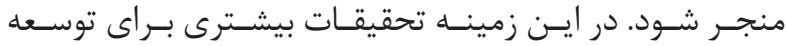

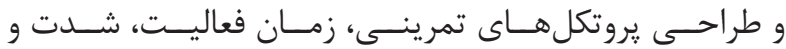

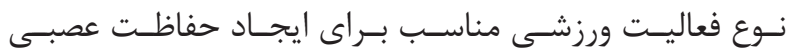

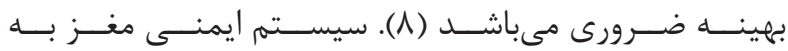

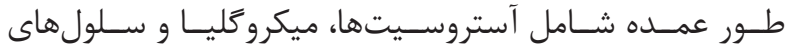

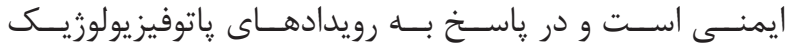

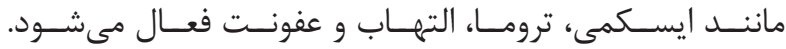

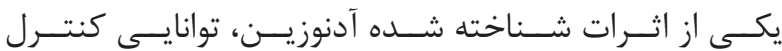

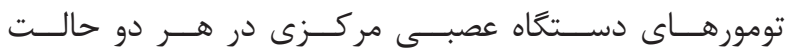

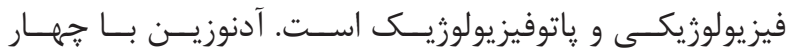

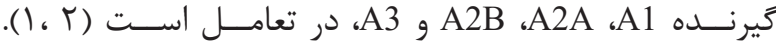

ممكـن اسـت فعـال سـازى برخـى از ايسن كيرندهــــا تشـديد

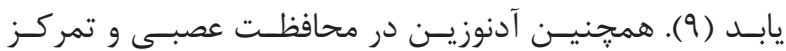

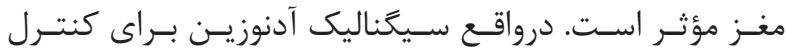

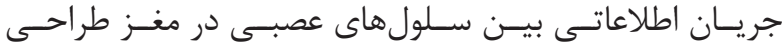

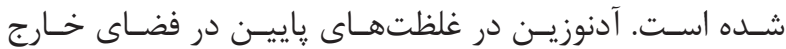

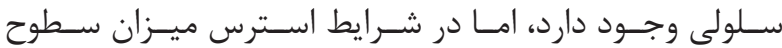

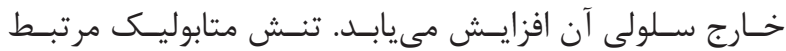

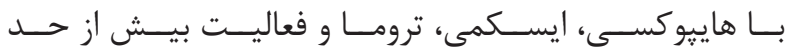

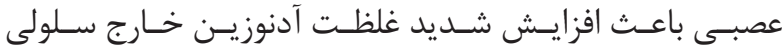

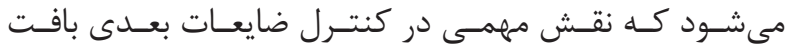

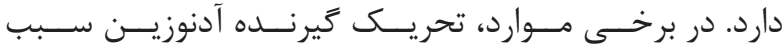

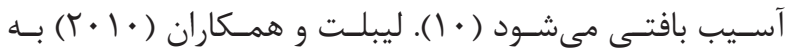

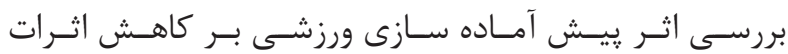

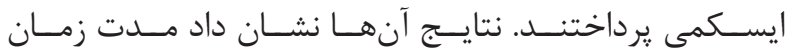

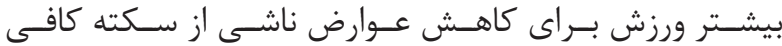

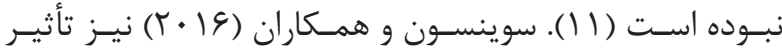

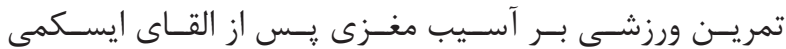

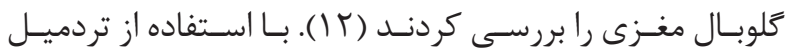

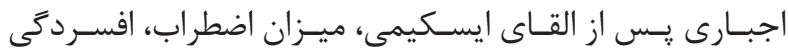

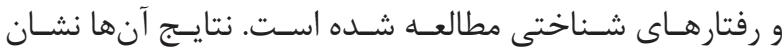

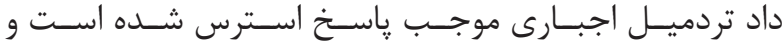

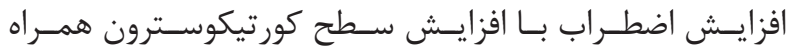

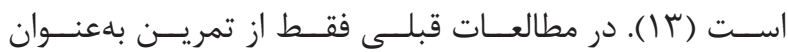

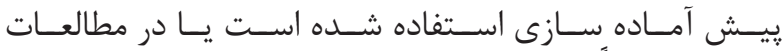

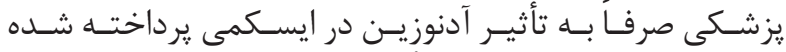

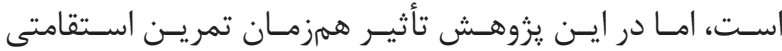

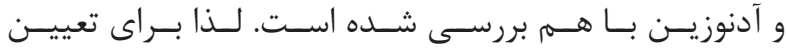

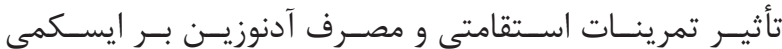

فعاليـت جسـمانى منظـهم و برنامههــاى تمرينـى مناسـب بــه

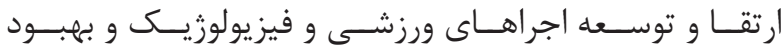

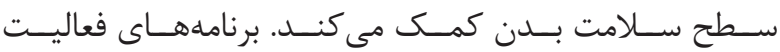

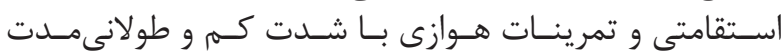

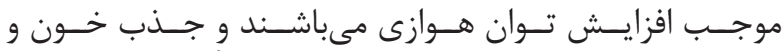

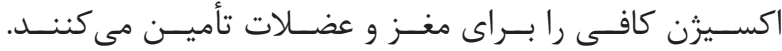

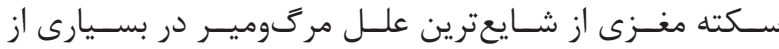

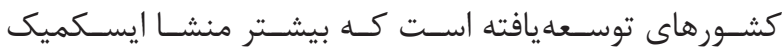

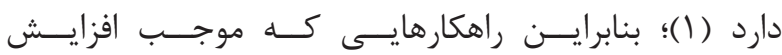

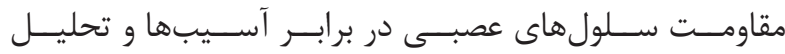

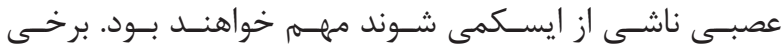

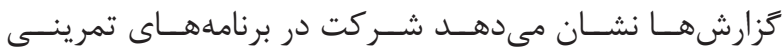

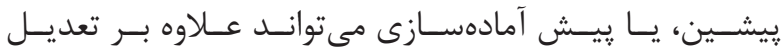

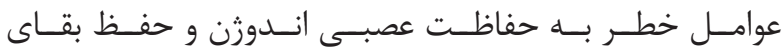

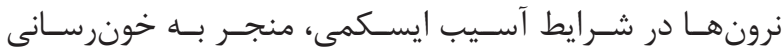

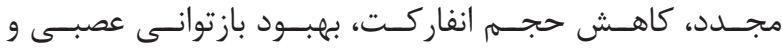

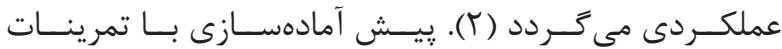

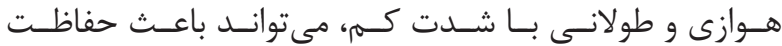

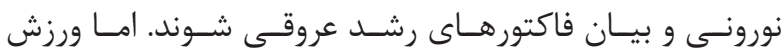

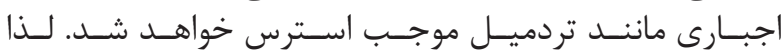

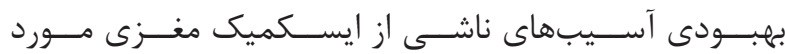

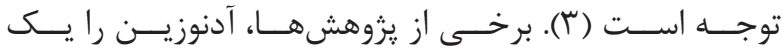

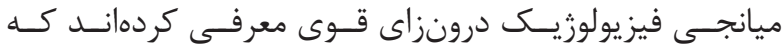

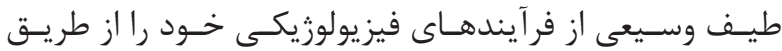

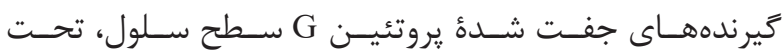

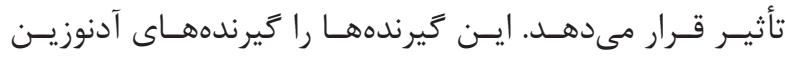

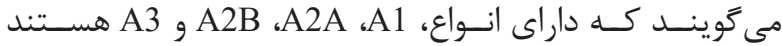

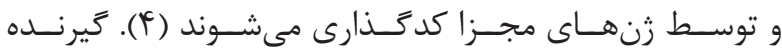

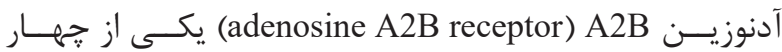

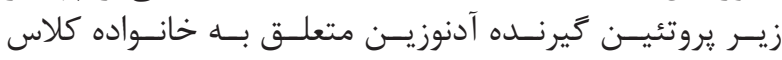

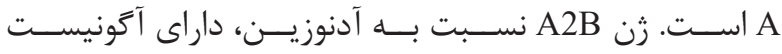

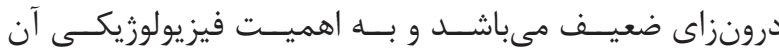

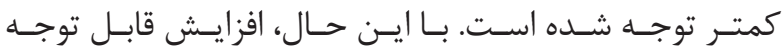

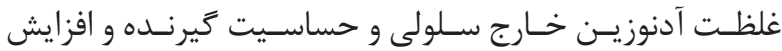

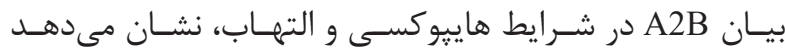

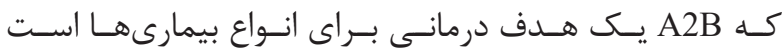

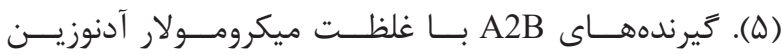

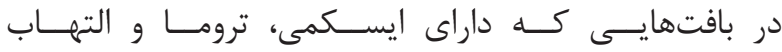

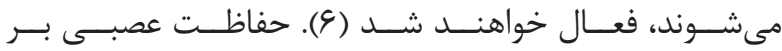

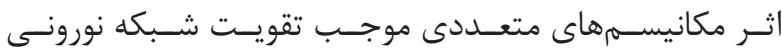

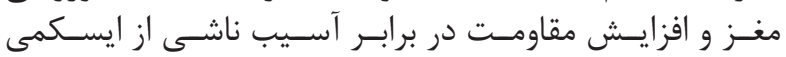

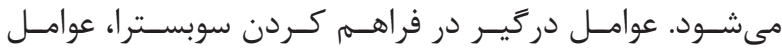

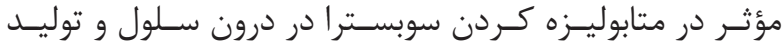

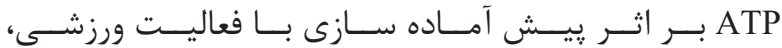

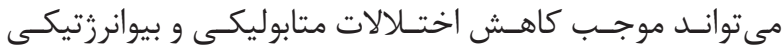


بــه وســيله ضربـان ســـنج (Polar/ فنلاتـد) كنتـرل مىشـــ.

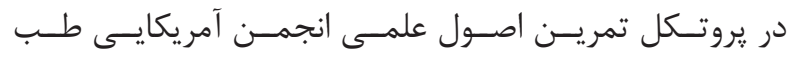

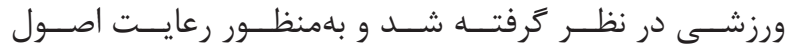

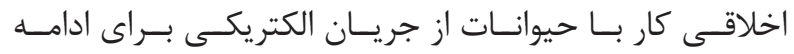

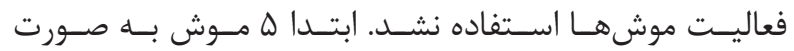

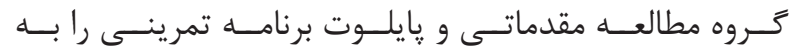

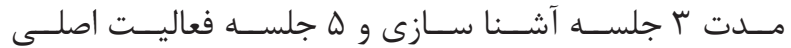

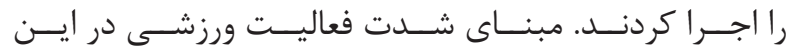

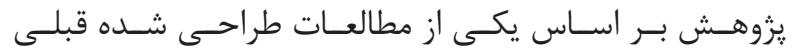

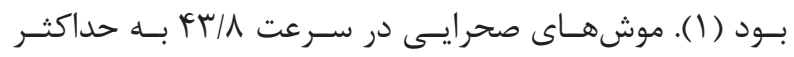

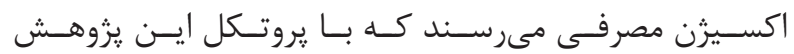

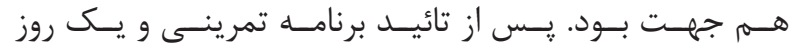

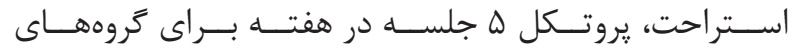

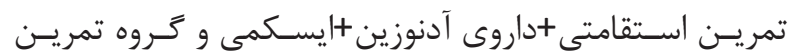

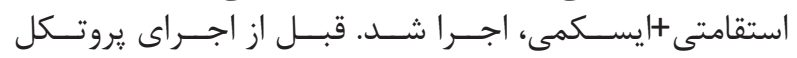

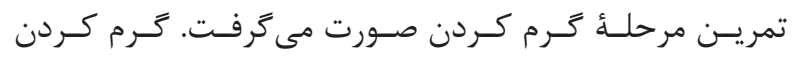

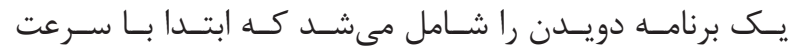

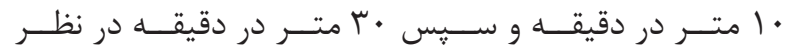

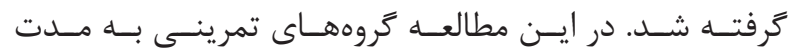

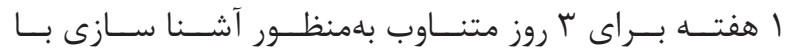

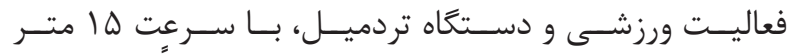

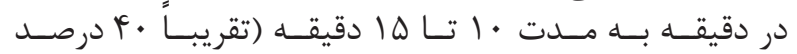

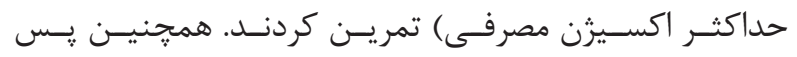

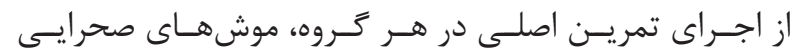

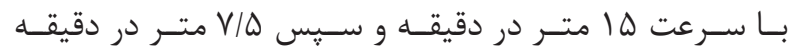

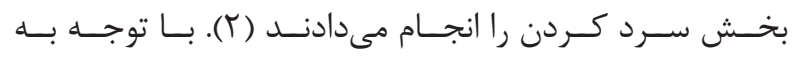

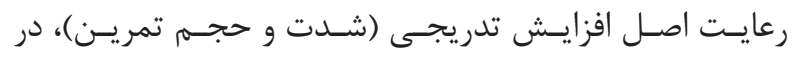

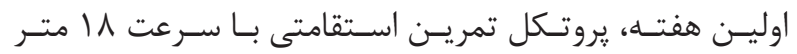

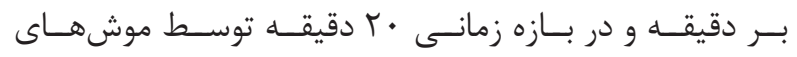

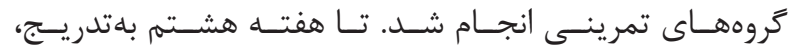

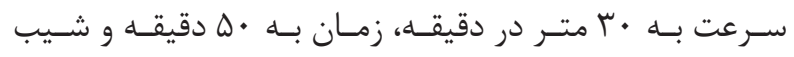

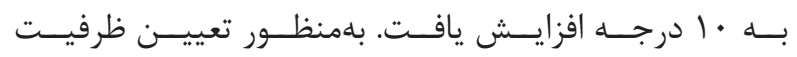

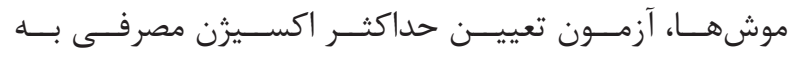

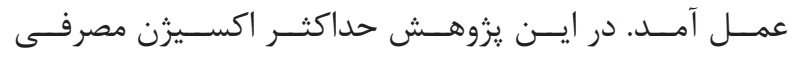

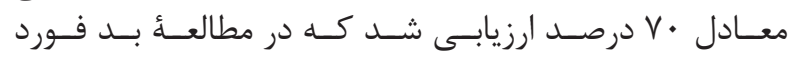

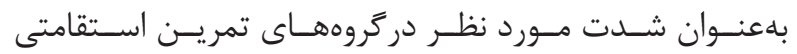

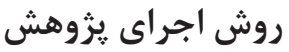

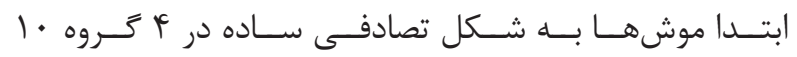

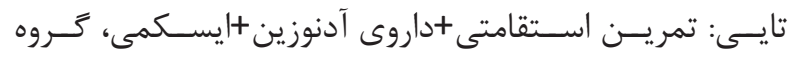

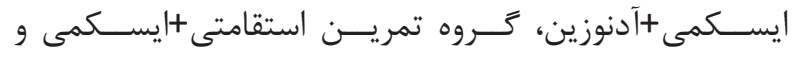

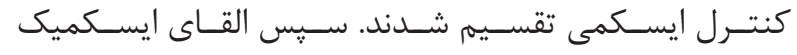

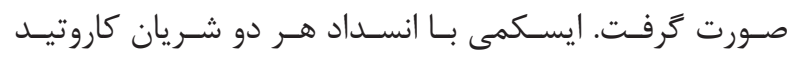

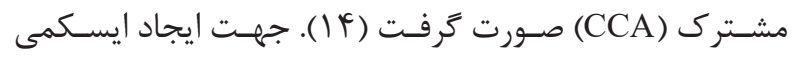

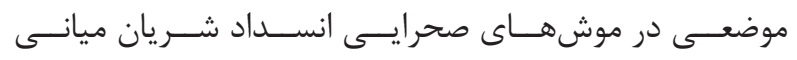

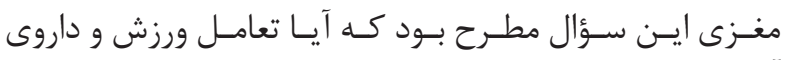

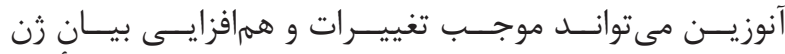

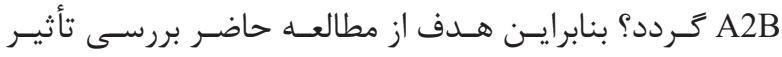

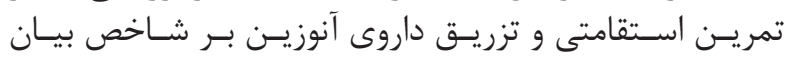

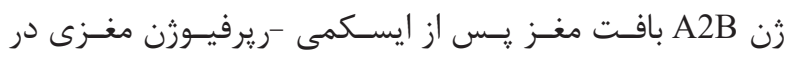

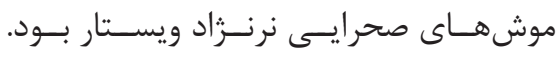

مواد و روشها

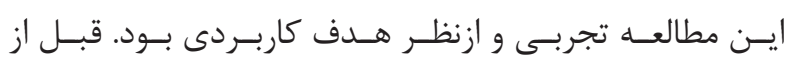

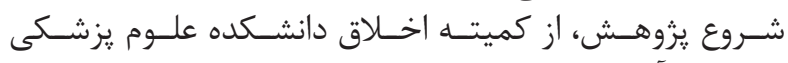

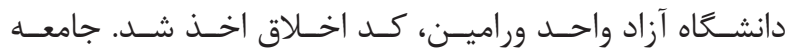

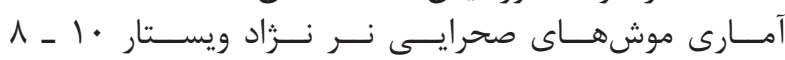

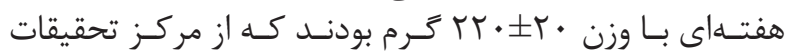

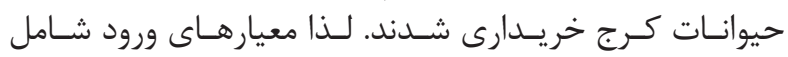

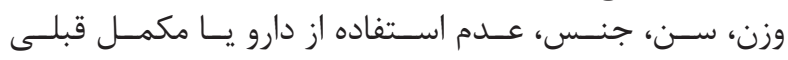

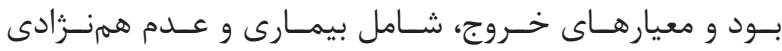

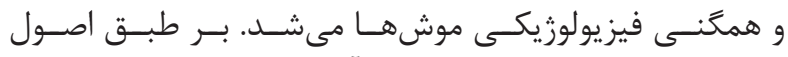

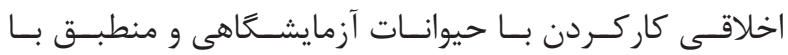

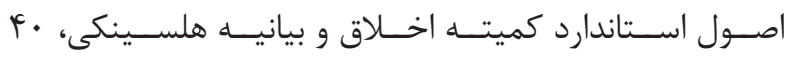

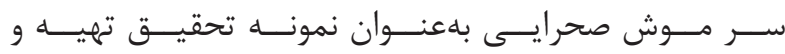

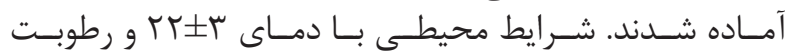

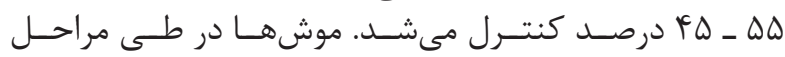

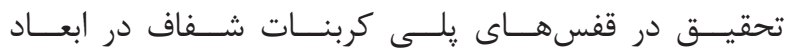

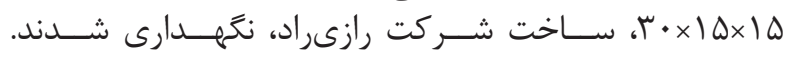

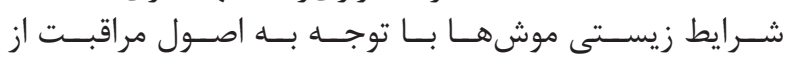

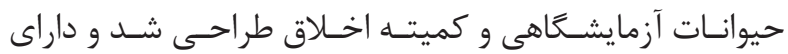

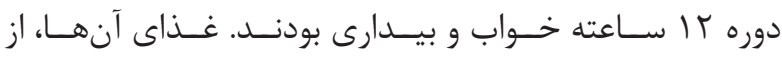

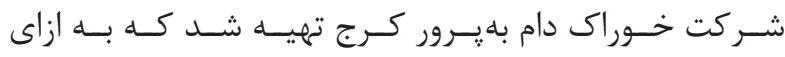

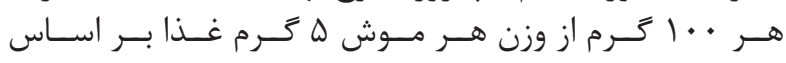

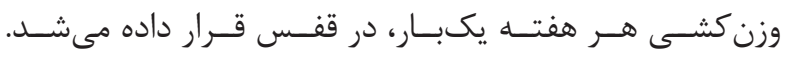

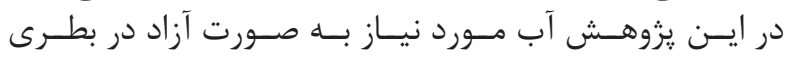

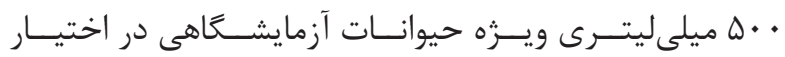

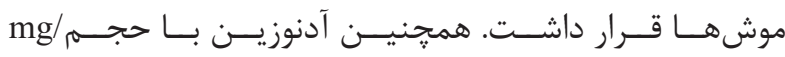

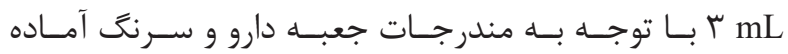

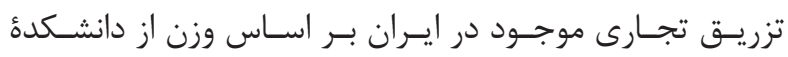

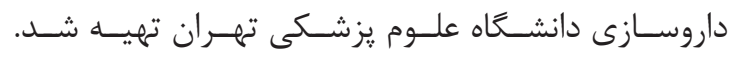

يروتكل تمرين

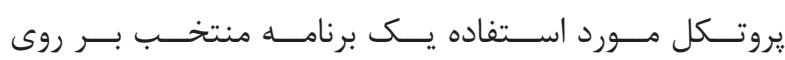

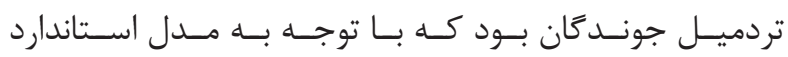

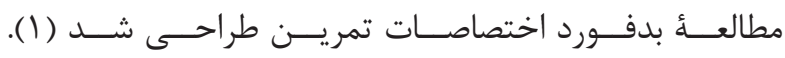

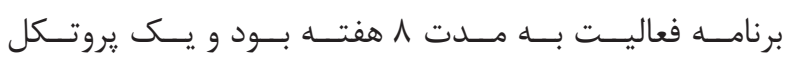

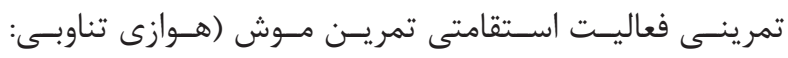

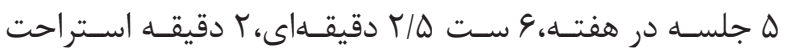

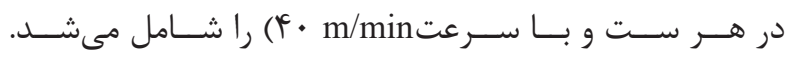

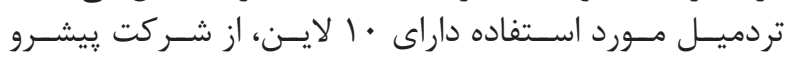

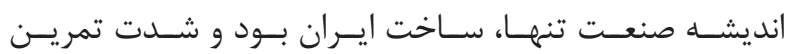




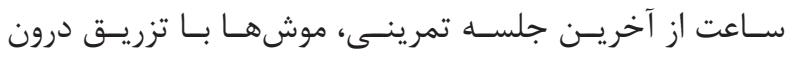

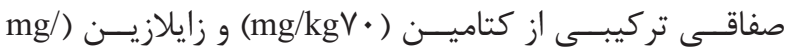

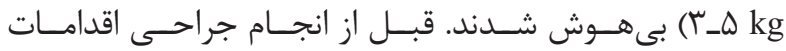

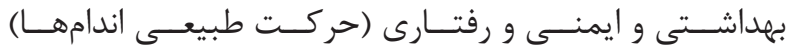

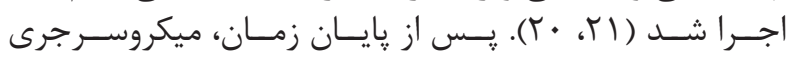

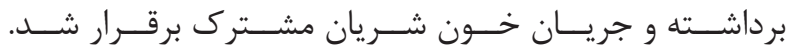

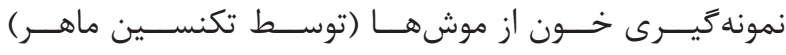

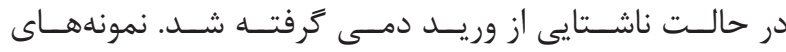

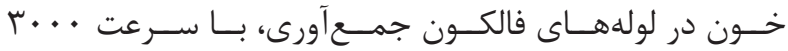

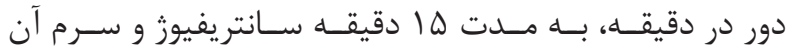

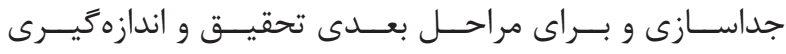

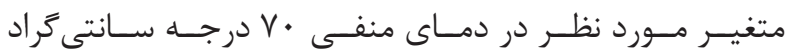

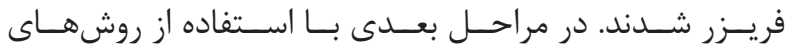

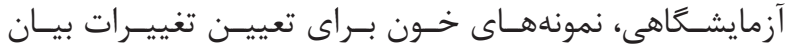

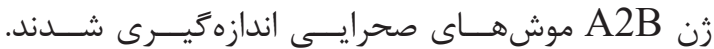

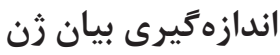

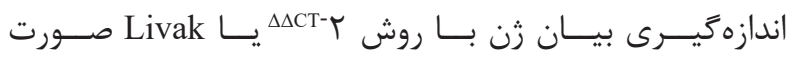

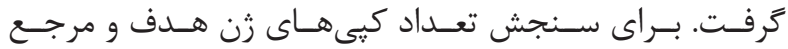

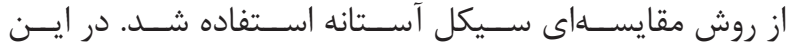

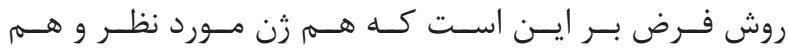

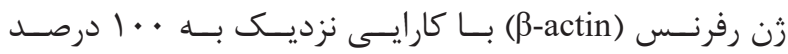

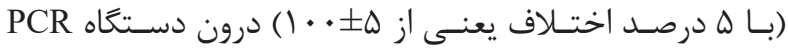

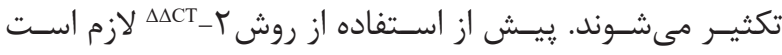

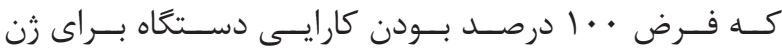

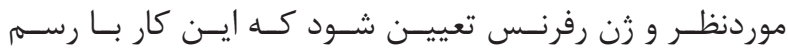

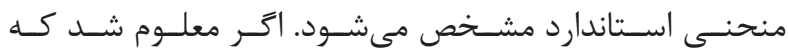

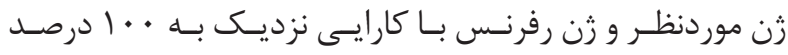

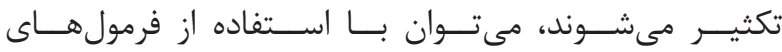

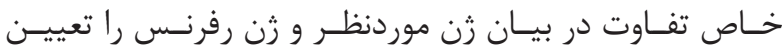

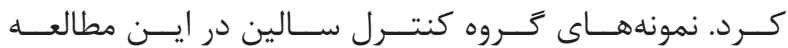

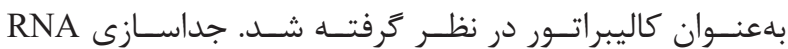

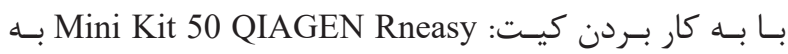

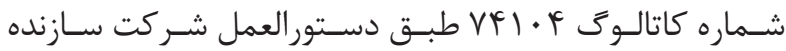

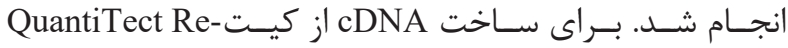
vبــ verse Transcription Kit cDNA synthesis Qiagen

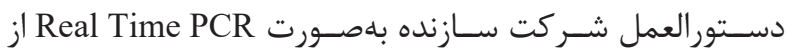

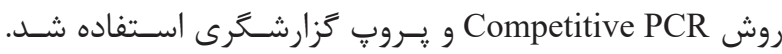

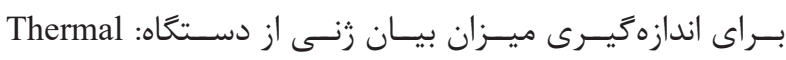
BIO RADC1000TM Cycler

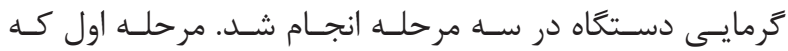

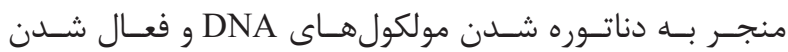

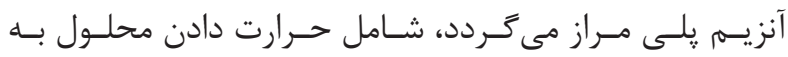

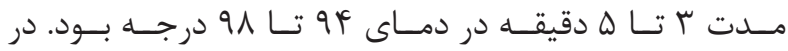

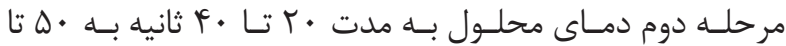

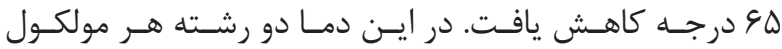

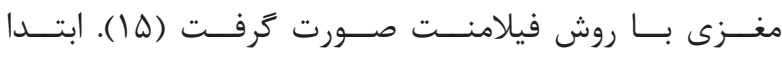

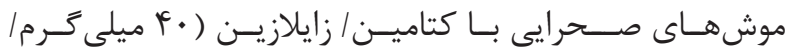

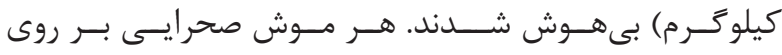

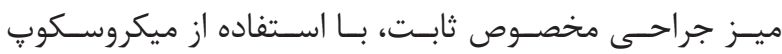

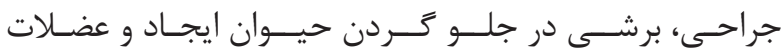

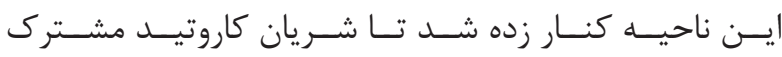

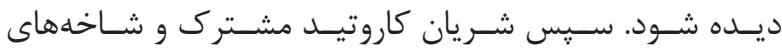

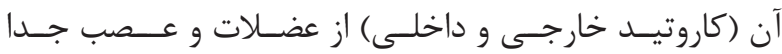

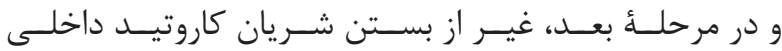

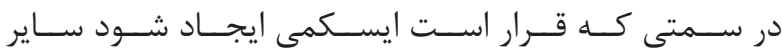

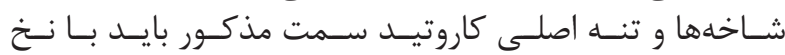

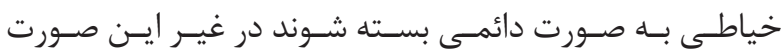

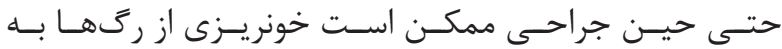

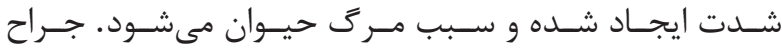

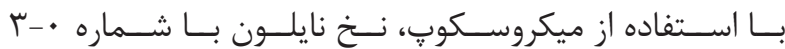

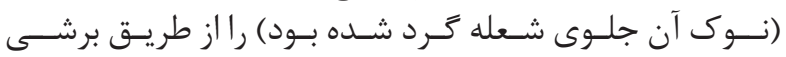

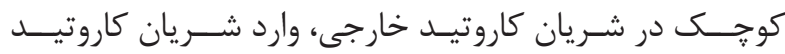

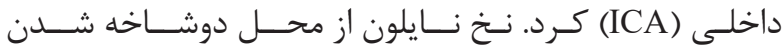

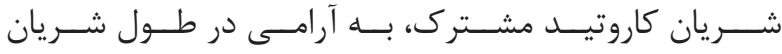

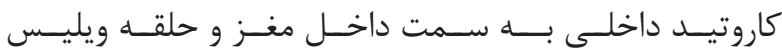

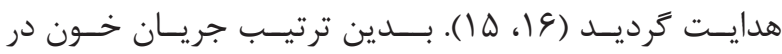

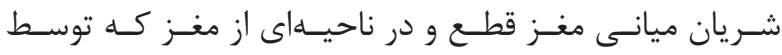

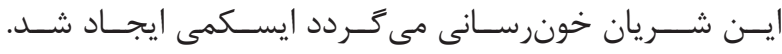

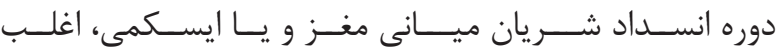

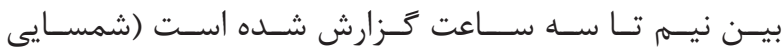

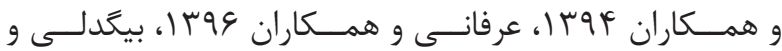

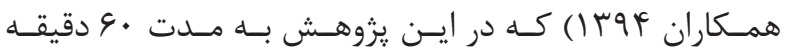

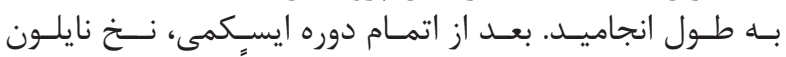

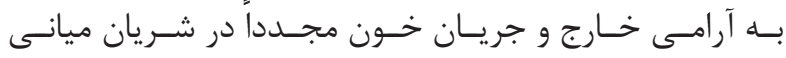

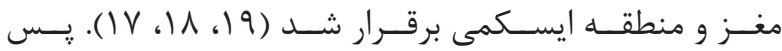

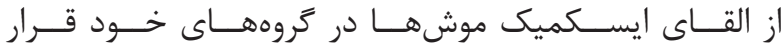

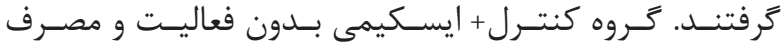

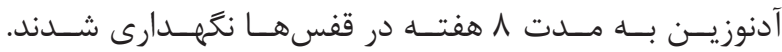

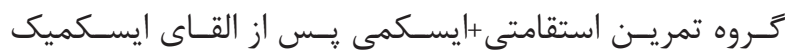

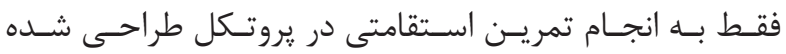

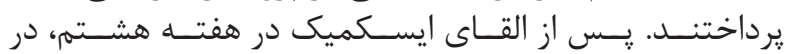

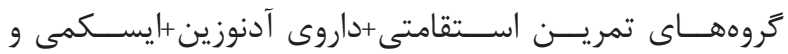

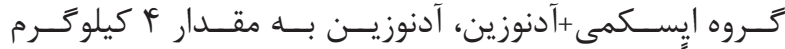

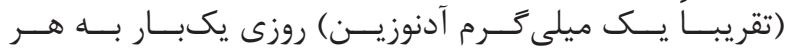

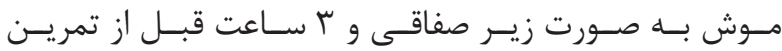

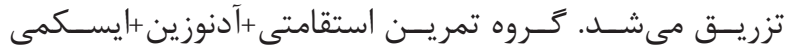

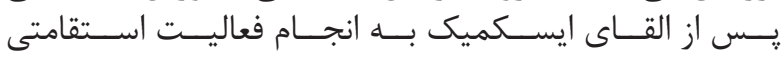

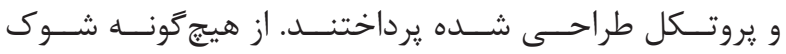

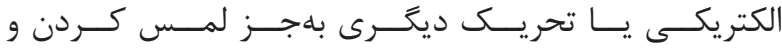

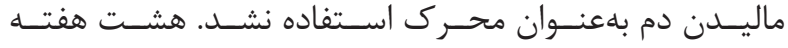

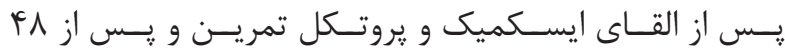




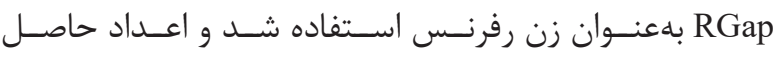

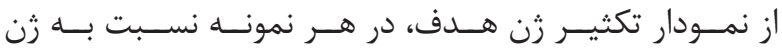

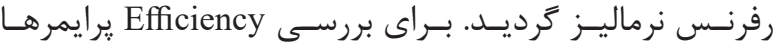

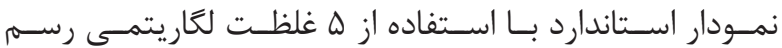

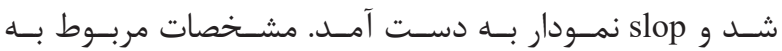

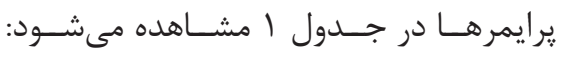

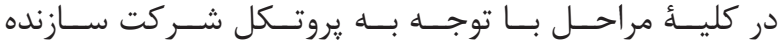

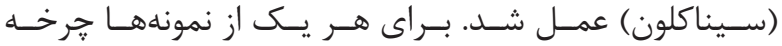

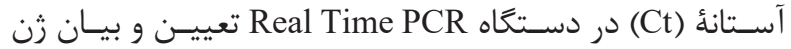
A2B

\section{روش تجزيلهوتحليل اطلاعات}

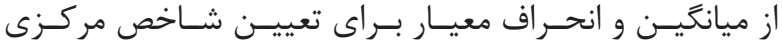

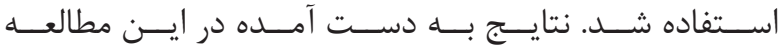

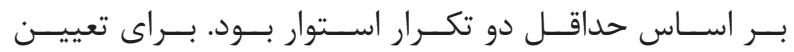

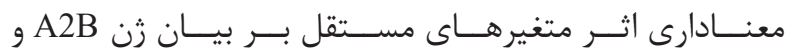

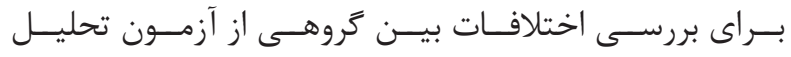

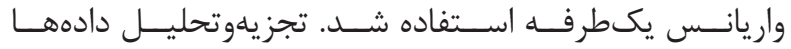

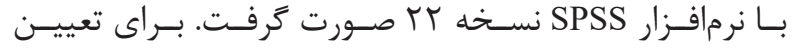

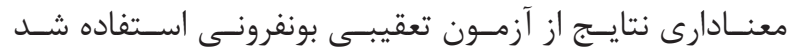

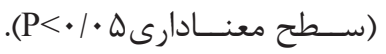

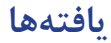

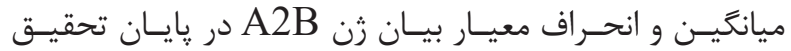

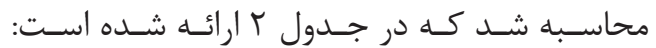

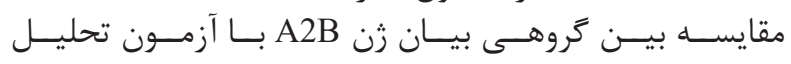

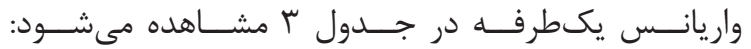

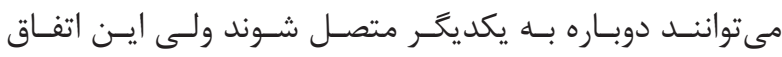

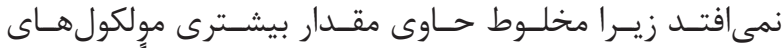

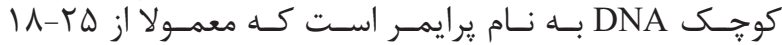

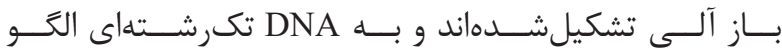

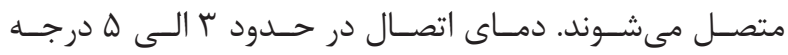

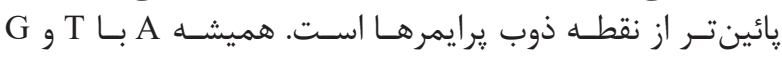

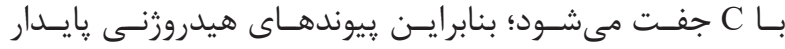

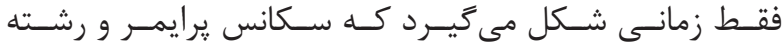

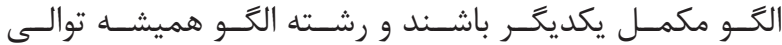

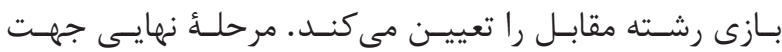

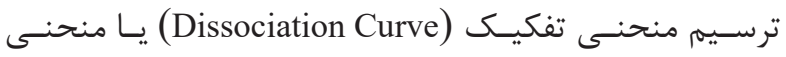

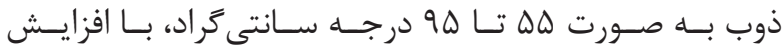

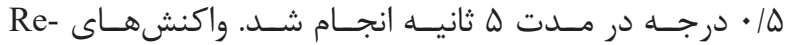
al-Time PCR

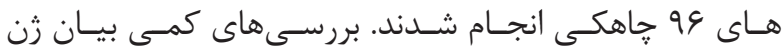

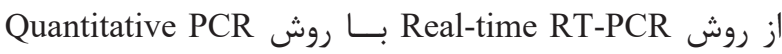

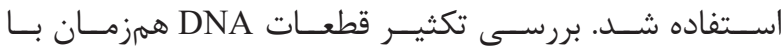

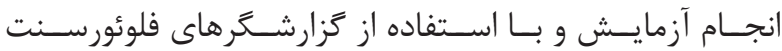

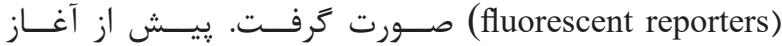

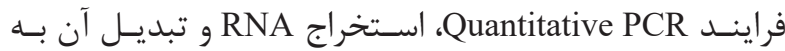

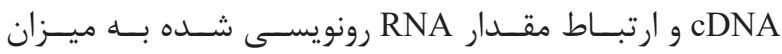

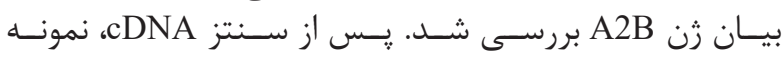

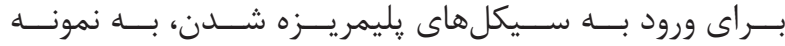

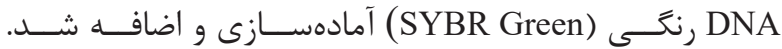

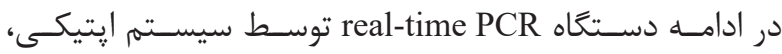

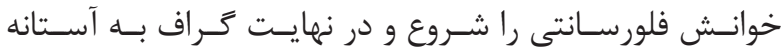

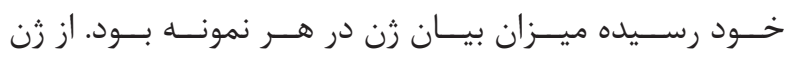

جدول ا- مشخصات مربوط به يرايمرهاى طراحىشده

\begin{tabular}{|c|c|c|c|c|}
\hline طول محصول & $\begin{array}{l}\text { Tm } \\
\left({ }^{\circ} \mathrm{c}\right)\end{array}$ & طول نوكلئوتيد & 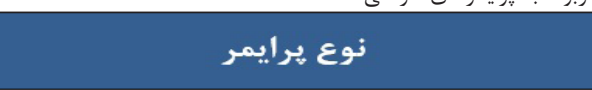 & رن \\
\hline \multirow{2}{*}{$19 \cdot b p$} & QI/rt & 11 & TGGCGCTGGAGCTGGTTA & \multirow{2}{*}{$\mathbf{A 2 B}$} \\
\hline & $\Delta \wedge / \Lambda$. & 11 & GCAAAGGGGATGGCGAAG & \\
\hline \multirow{2}{*}{$|r| \mathrm{bp}$} & $8 / / \Delta \Lambda$ & tr & AAGTTCAACGGCACAGTCAAGG & \multirow{2}{*}{ RGap } \\
\hline & SI/rT & tr & CATACTCAGCACCAGCATCACC & \\
\hline
\end{tabular}

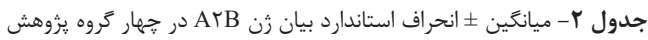

\begin{tabular}{|c|c|c|}
\hline انحراف استاندارد 土 ميانكين & 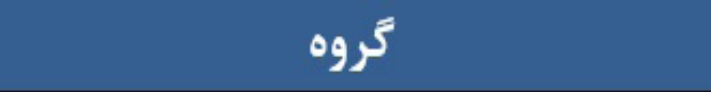 & متغير \\
\hline$r \cdot / \Gamma \mid \pm 1 / r \Delta$ & تمرين استقامتى+ ايسكمى & \multirow{4}{*}{ A2B } \\
\hline$r r / \cdot G \pm r / V \Delta$ & كنترل - ايسكمى & \\
\hline$r I / 1 \pm \cdot / \cdot \varphi$ & داروى آدنوزين+ ايسكمى & \\
\hline $1 N / \Delta \cdot \pm \cdot / \Delta \varphi$ & تمرين استقامتى + دارو آدنوزين + ايسكمى & \\
\hline
\end{tabular}




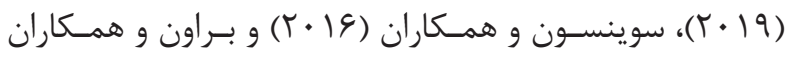

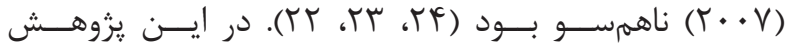

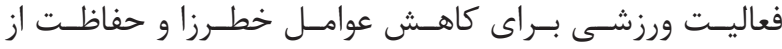

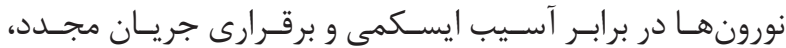

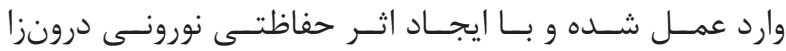

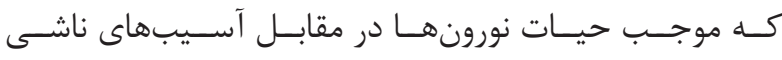

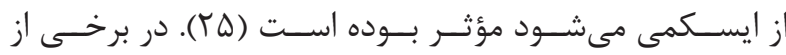

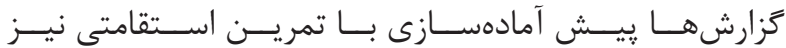

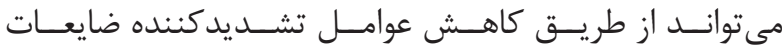

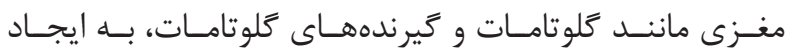

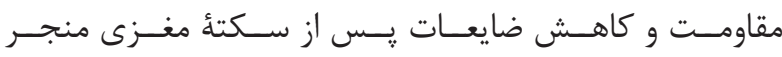

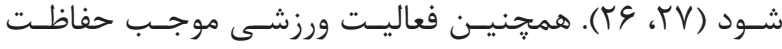

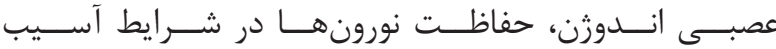

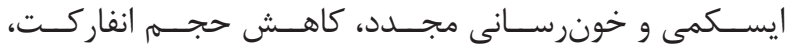

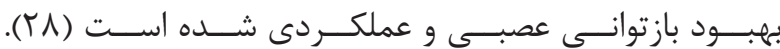

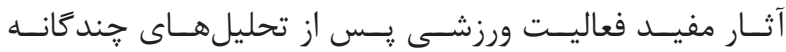

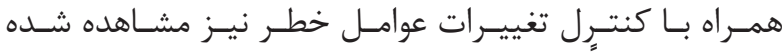

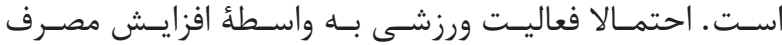

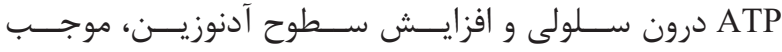

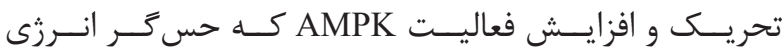

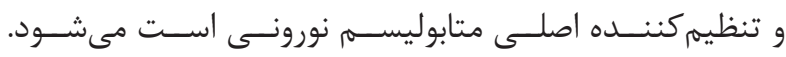

$$
(\mathrm{P}<\cdot / \cdot \Delta) *
$$

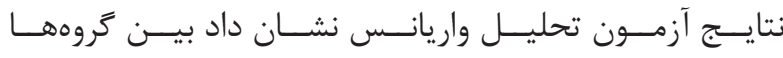

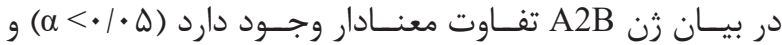

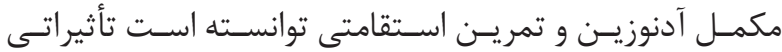

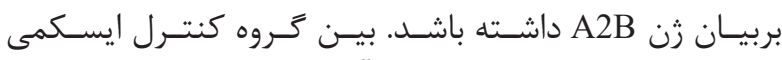

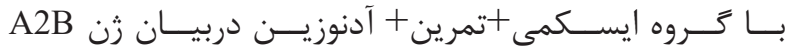

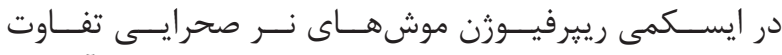

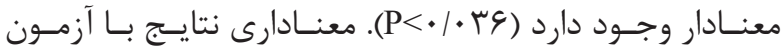

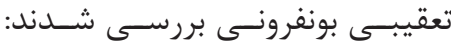

$$
\begin{aligned}
& (\mathrm{P}<\cdot / \cdot \Delta)^{*}
\end{aligned}
$$

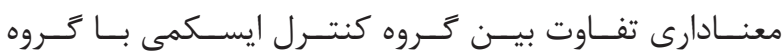

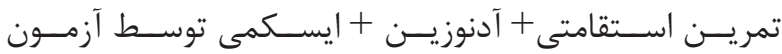

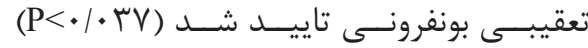

$$
\text { بحث و نتيجه كيرى }
$$

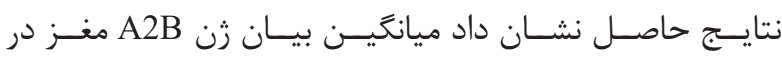

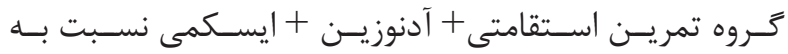

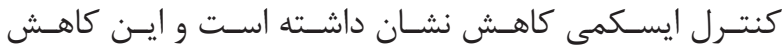

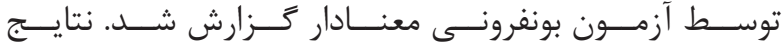

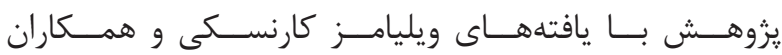

\begin{tabular}{|c|c|c|c|c|c|c|}
\hline P-Value & $\mathbf{F}$ & ميانكين مجذورات & درجه آزادى & مجموع مجذورات & منبع تغييرات & متغير \\
\hline \multirow{3}{*}{$\cdot \mid \cdot r \varphi^{*}$} & \multirow{3}{*}{$4 / 99$} & $9 / 99$ & r & rN/99 & بين گروهى & \multirow{3}{*}{ A2B } \\
\hline & & $r / \cdot \varphi$ & $\Lambda$ & $18 / 4 \lambda$ & درون گروهى & \\
\hline & & $r / \cdot \varphi$ & 11 & $F \Delta / \& V$ & كل & \\
\hline
\end{tabular}

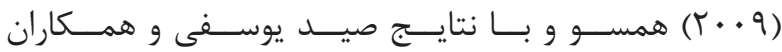

جدول بـ- نتايج تحليل واريانس يكطرفه بيان زن ArB

\begin{tabular}{|c|c|c|}
\hline P-Value & L. & \\
\hline •/ץ & كنترل ايسكمى & \multirow{3}{*}{ تمرين + ايسكمى } \\
\hline 1 & آدنوزين + ايسكمى & \\
\hline - /9 & تمرين + آدنوزين + ايسكمى & \\
\hline 1 & آدنوزين + ايسكمى & \multirow{2}{*}{ كنترل ايسكمى } \\
\hline$\cdot / \cdot r V^{*}$ & تمرين + آدنوزين + ايسكمى & \\
\hline • & تمرين + آدنوزين + ايسكمى & آدنوزين + ايسكمى \\
\hline
\end{tabular}

جدول F- نتايج حاصل از آزمون تعقيبى بونفرونى بيان رن AYB در كروههاى موردتحقيق 
جســبند

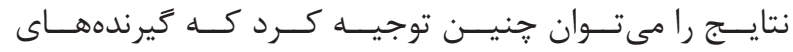

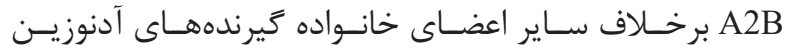

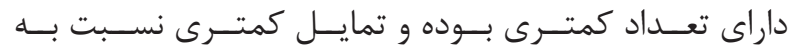

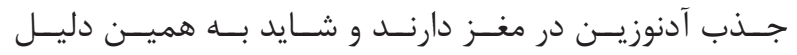

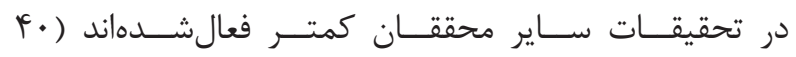

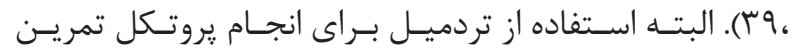

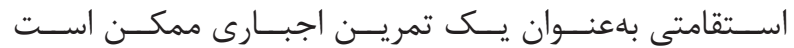

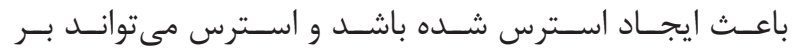

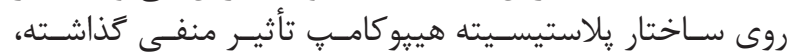

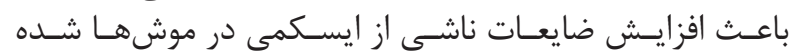

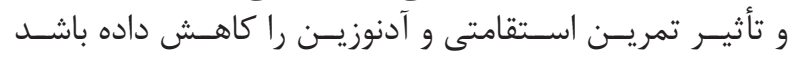

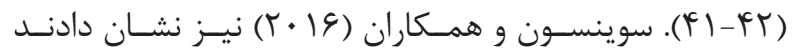

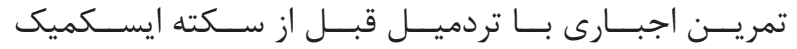

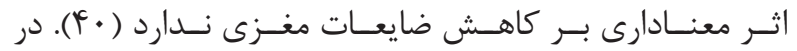

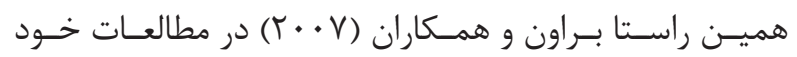

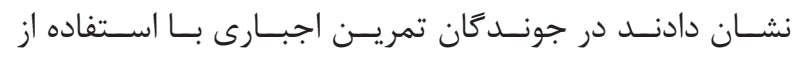

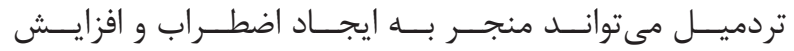

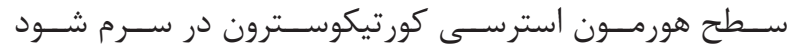

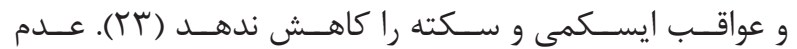

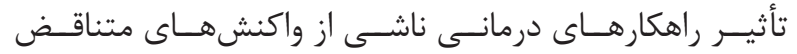

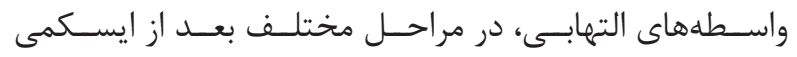

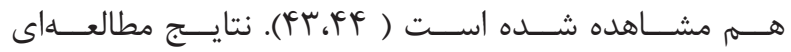

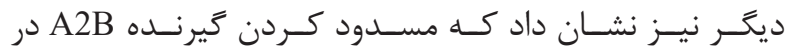

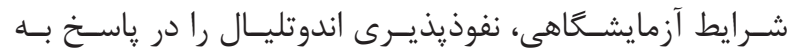

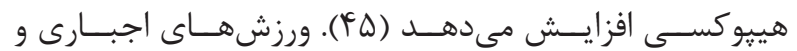

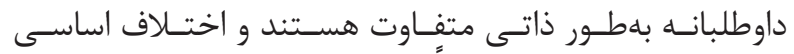

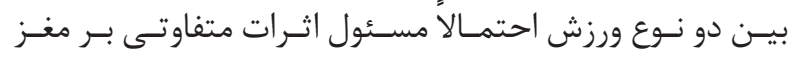

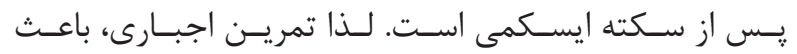

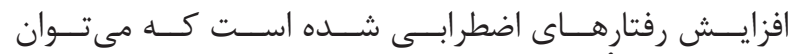

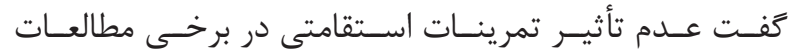

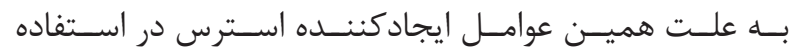

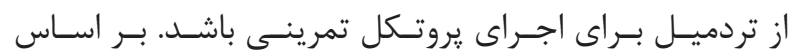

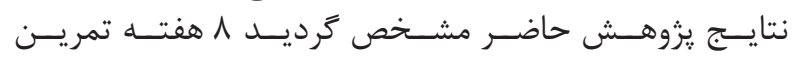

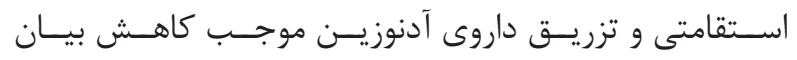

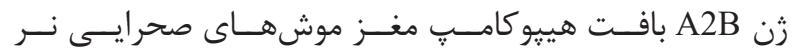

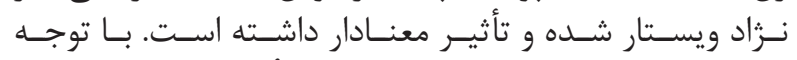

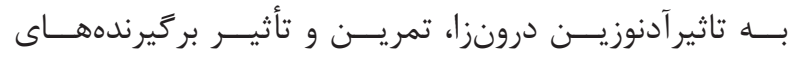

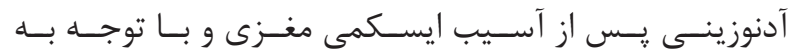

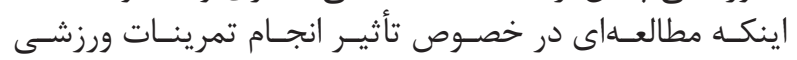

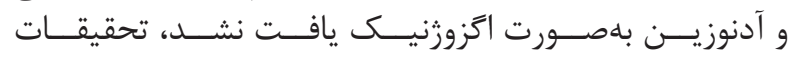

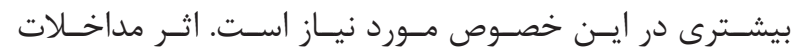

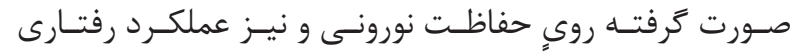

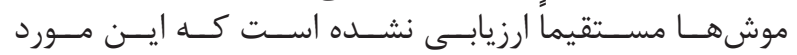

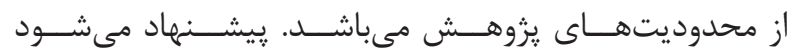

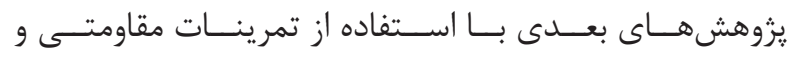

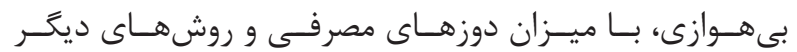

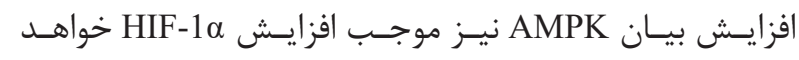

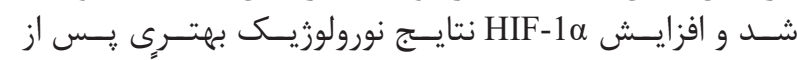

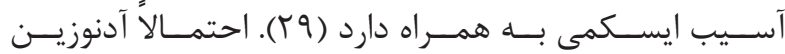

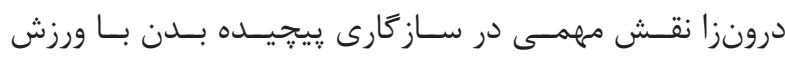

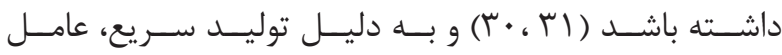

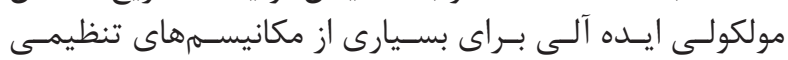

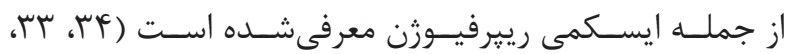

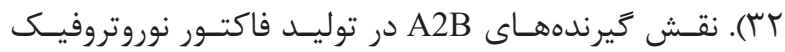

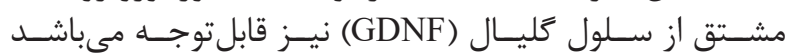

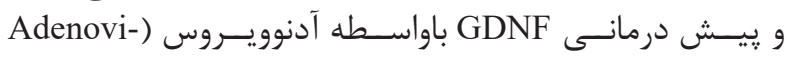

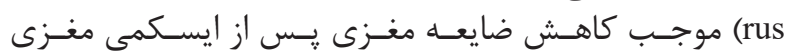

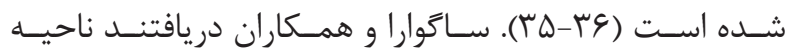

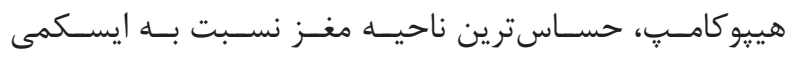

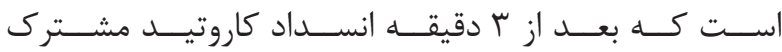

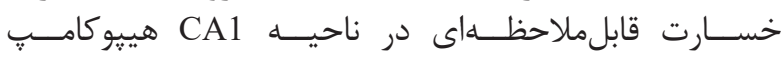

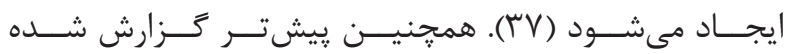

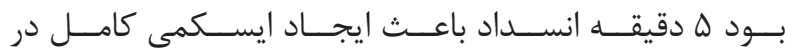

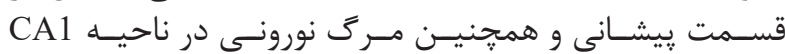

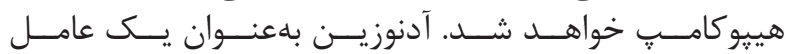

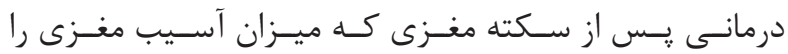

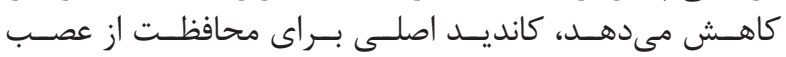

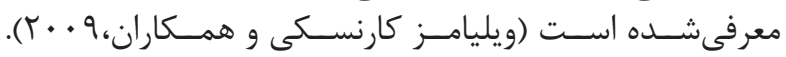

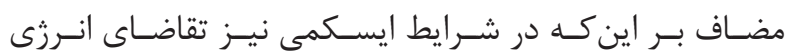

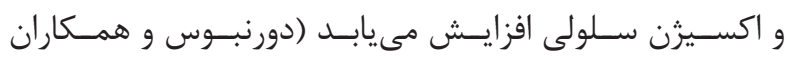

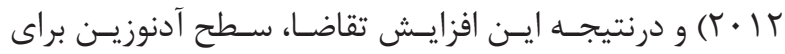

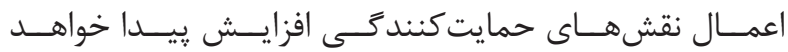

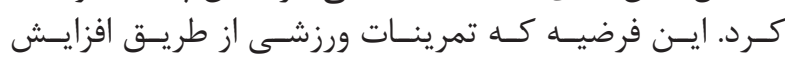

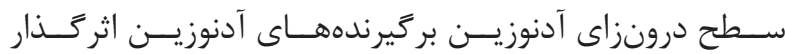

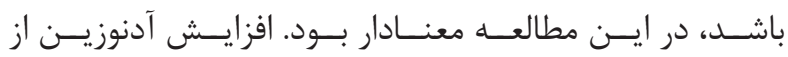

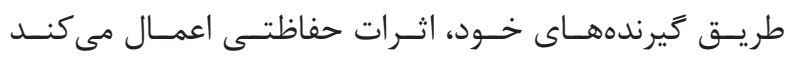

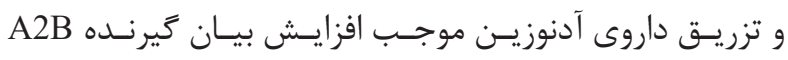

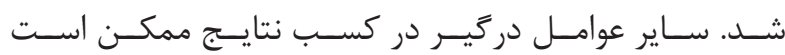

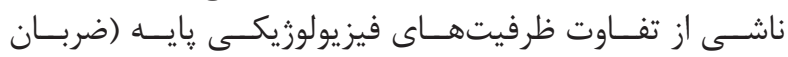

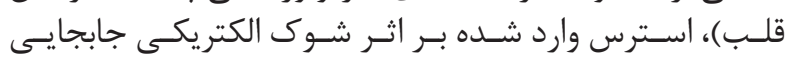

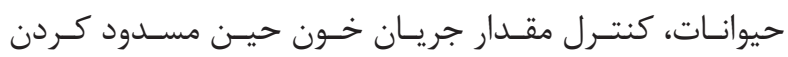

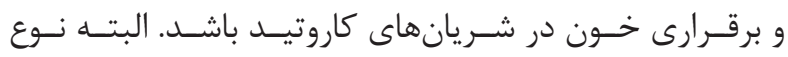

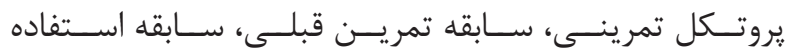

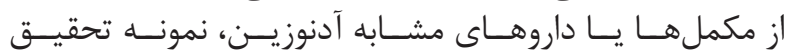

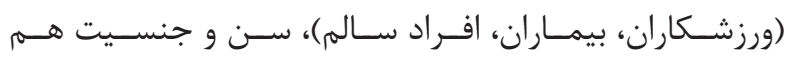

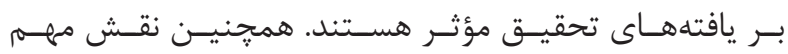

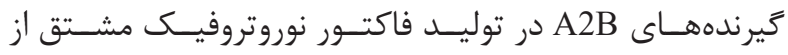

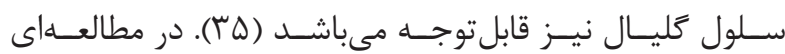

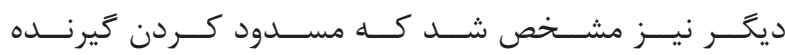

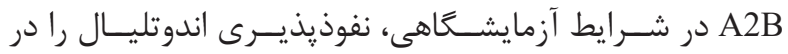

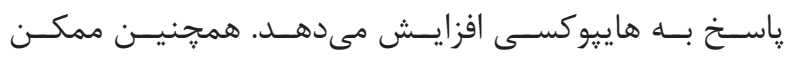

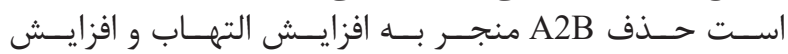




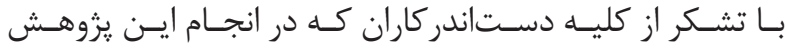

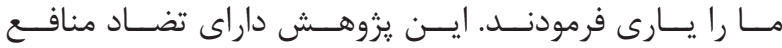

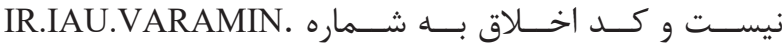

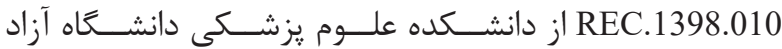

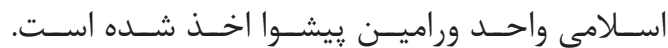

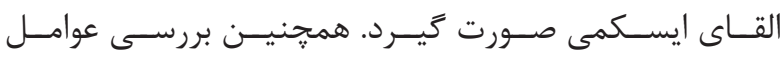

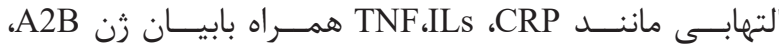

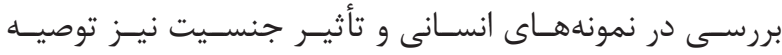

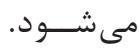
تشكر و قدردانى

منابع

1. Goldstein LB, Adams R, Becker K, Furberg CD ,Gorelick PB, Hademenos G, et al. Primary prevention of ischemic stroke. Circulation 2001; 103(1): 163-82.

2. Hu G, Barengo NC, Tuomilehto J, Lakka TA, Nissinen A, Jousilahti P. Relationship of physical activity and body mass index to the risk of hypertension: a prospective study in Finland. Hypertension 2004; 43(1): 25-30.

3. McEwen BS.Stress and hippocampal plasticity. Annu Rev Neurosci 1999; 22: 1-5.

4. Headrick JP ,Peart JN, Reichelt ME, Haseler LJ.Adenosine and its receptors in the heart: regulation, retaliation and adaptation. Biochimica et Biophysica Acta (BBA)-Biomembranes 2011; 1808(5): 1413-428.

5. Zadhoush F, Mojtaba Panjehpour. Physiological role of adenosine and its receptors in tissue hypoxia-induced angiogenesis. Physiology and Pharmacology,16(3), 209-221 Autumn 2012 [Article in Persian]

6. Eltzschig HK. Adenosine: an old drug newly discovered. Anesthesiology 2009; 111(4): 904-15.

7. Wang CX, Yang T and Shuaib A. An improved version of embolic model of brain ischemic injury in the rat $\mathrm{J}$ Neurosci Methods 2001; 109(2): 147-51.

8. Zheng YQ, Liu JX,Wang JN,Xu L. Effects of crocin on reperfusion-induced oxidative/nutritive injury to cerebral micro vessels after global cerebral ischemia. Brain Res 2007; 1138: 86-94.

9. Hosseini M ,Sohrab Hajizadeh, Yaghoub Fathollahi, Mojtaba Golmohammadi, Batoul Erfani, Ali Heidarian Pour. The role of adenosine A2 receptors in regulation of pial vessels blood flow in anesthetized morphine dependent rats. Physiology and Pharmacology, 12(1), 22-30 Spring 2008 [Article in Persian]

10. Adair TH. Growth regulation of the vascular system an emerging role for adenosine Am J Physiol Regul Integr Comp Physiol 2005; 289(2): 283-96.
11. Haskó G, Pacher P, Vizi S, Peter I. Adenosine receptor signaling in the brain immune system, Trends Pharmacol Sci. 2005; 26(10): 511-16.

12. Liebelt B, Papapetrou P, Ali A, Guo M, Ji X, Peng C, et al. Exercise preconditioning reduces neuronal apoptosis in stroke by up-regulating heat shock protein-70 (heat shock protein-72) and extracellular-signal-regulatedkinase 1/2. .Neuroscience 2010; 14; 166(4): 1091-100.

13. Svensson M, Rosvall P, Boza-Serrano A, Andersson E, Lexell J, Deierborg T. Forced treadmill exercise can induce stress and increase neuronal damage in a mouse model of global cerebral ischemia Neurobiology of stress 2016; 5: 8-18.

14. Shamsaei N,Aboutaleb N,Erfani S, Khaksari M. Effect of Exercise Preconditioning on Memory Deficits and Neuronal Cell Death in the CA3 Pyramidal Cells of the Rat Hippocampus Following Transient Global Cerebral Ischemia. Journal of Ardabil University of Medical Sciences, 2015; 15(3): p. 291-300.

15. Vakili A. Mini-review for methods of induction experimental ischemia stroke: type of model, evaluation ischemic damage and neurological deficit. koomesh. 2006; 8(1): 1-10.

16. Mohammadi M T, Shid Moosavi S M, Dehghani G A. Inhibition of nitric oxide synthase activity improves focal cerebral damage induced by cerebral ischemia/ reperfusion in normotensive rats. Physiol Pharmacol. 2010; 14(1): 23-33.

17. Erfani H, Taheri Kalani AH, Shamsaei N.The protective effect of aerobic training on cognitive impairment and motor dysfunction in male rats following cerebral ischemia.Pars J Med Sci 2017; 15(3): 24-33.

18. Bigdeli MR, Mostafavi H, Gholamzadeh R, Eskandari M. Pretreatment Effect of Erythropoietin on Brain Tissue Water Content after Brain Ischemia Induction by Middle Cerebral Artery Occlusion (MCAO) in Male Wistar Rats. 


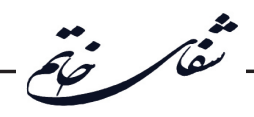

Scientific, Research Journal of Zanjan University of Medical Sciences 2015; 24(104): 59-72.

19. Jozaie A, Movahedi M, Khosravi M, Golab F. The effects of adenosine injection after of brain ischemia reperfusion injury on gene expression of NF-kB/p65 and activity level of ROS in hippocampus tissue of male wistar rats. Razi J Med Sci. 2019; 26(2): 74-84.

20. Vakili A ,Mohammad Reza Eianali, Ahmad Reza Bandegi, The protective effects of Saffron against the oxidative damage in a transient model of focal cerebral ischemia in rats, Tehran Univ Med J. 2011; 69(7): 40512.

21. Seydyousefi M, Fallah mohammadi Z, Moazzami M, Yaghoubi A, Faghfoori Z. Impact of Early Endurance Training on Improvement of Brain Damage in CA1 Region of Hippocampus and Expression of A2A Protein Following Ischemic Stroke in Rats. J Isfahan Med Sch 2019; 37(526): 485-92.(in Persian).

22. Brown DA, Johnson MS, Armstrong CJ, Lynch JM, Caruso NM, Ehlers LB, et al Short-term treadmill running in the rat: what kind of stressor is it? Journal of applied physiology 2007; 103(6): 1979-85.

23. Williams-Karnesky RL, Stenzel-Poore MP. Adenosine and stroke: maximizing the therapeutic potential of adenosine as a prophylactic and acute neuroprotectant Current neuropharmacology 2009; 7(3): 217-27.

24. Takahashi H, Takada Y, Urano T, Takada A. 5-HT4 receptors in the hippocampus modulate rat, locomotor activity, Hippocampus.2002; 12(3): 304-10.

25. Smith PF,Darlington CL, Zhen Y. The effects of complete vestibular differentiation on spatial memory and the hippocampus in the rat: the Dunedin experience. Multisens Res 2015; 28(5-6): 461-85.

26. Obrenovitch TP. Molecular physiology of preconditioning-induced brain tolerance to ischemia. Physiological reviews 2008; 88(1): 211-47.

27. Fredholm BB,IJzerman AP,Jacobson KA, Linden J,Müller CE. International Union of Basic and Clinical Pharmacology LXXXI Nomenclature and classification of adenosine receptors an update Pharmacol Rev 2011; 63(1): p1-34.
28. Dornbos III D, Ding Y. Mechanisms of neuroprotection underlying physical exercise in ischemia-reperfusion injury. Brain Injury-Pathogenesis, Monitoring, Recovery and Management: IntechOpen; 2012.

29. Bansal S, Sangha KS, Khatri P. Drug treatment of acute ischemic stroke. Am J Cardiovasc 2013; 13: 57-69.

30. Katayama K,Matsuo H,Ishida K, Mori S,Miyamura M:Intermittent hypoxia improves endurance performance and submaximal exercise efficiency. High Alt Med Biol 2003; 4: 291-304.

31. Minami M, Katayama T, Satoh M. Brain cytokines and chemokines : roles in ischemic injury and pain. Journal of pharmacological sciences 2006; 100(5): 46170 .

32. Liu S,Zhang L, Wu Q, Wu Q, Wang T. Chemokine CCL2 induces apoptosis in cortex following traumatic brain injury. Journal of Molecular Neuroscience 2013; 51(3): 1021-9.

33. Wiesner S, Haufe S, Engeli S, Mutschler H, Haas U, Luft FC, Jordan J:Influences of normobaric hypoxia training on physical fitness and metabolic risk markers in overweight to obese subjects. Obesity (Silver Spring) 2010; 18: 116-20.

34. Correia SC,Santos RX, Perry G,Zhu X,Moreira PI, Smith MA. Mitochondria: the missing link between preconditioning and neuroprotection J Alzheimers Dis 2010; 20(2): S475-85

35. Cotman CW, Berchtold NC and LA Christie. Exercise builds brain health: key roles of growth factor cascades and inflammation Trends Neurosci 2007; 30(9): 464-72.

36. Sugawara T, Lewén A, Noshita N, Gasche Y, Chan PH. Effects of global ischemia duration on neuronal, astroglial, oligodendroglial and microglial reactions in the vulnerable hippocampal CA1 subregion in rats. Journal of neurotrauma 2002; 19(1): 85-98.

37. Curry A,Guo M, Patel R, Liebelt B, Sprague S,Lai Q, et al. Exercise pre-conditioning reduces brain inflammation in stroke via tumor necrosis factor- $\alpha$, extracellular signalregulated kinase $1 / 2$ and matrix metalloproteinase- 9 activity. Neurol Res 2010; 32(7): 756-62.

38. Clark RS,Kochanek PM, Schwarz MA,Schiding JK, Turner DS, Chen M,et al. Inducible nitric oxide 
synthase expression in cerebrovascular smooth muscle and neutrophils after traumatic brain injury in immature rats. Pediatr Res 1996; 39(5): 784-90.

39. Cohen-Cory S,Kidane AH, Shirkey NJ,Marshak S. Brain-derived neurotrophic factor and the development of structural neuronal connectivity Dev Neurobiol 2010; 70(5): 271-88.

40. Beart PM, O'Shea RD. Transporters for L-glutamate: an update on their molecular pharmacology and pathological involvement. Br J Pharmacol 2007; 150(1): 5-17.

41. Mathers JL,Farnfield MM, Garnham AP, Caldow MK, Cameron-Smith D, Peake JM. Early inflammatory and myogenic responses to resistance exercise in the elderly. Muscle \& nerv 2012; 46(3): 407-12.

42. Kim SU, de Vellis J.Microglia in health and disease.
J Neurosci Res 2005; 81(3): 302-13.

43. Mota BC, Pereira L, Souza MA, Almeida Silva LF, Magni DV, Oliveira Ferreira AP, et al. Exercise pre-conditioning reduces brain inflammation and protects against toxicity induced by traumatic brain injury:behavioral and neurochemical approach. Neurotox Res 2012; Feb 21(2): 175-84.

44. Hankey GJ. Potential new risk factors for ischemic stroke: what is their potential? Stroke 2006; 37: 2181188.

45. Carlin JL, Grissom N, Ying Z, Gomez-Pinilla F, Reyes TM. Voluntary exercise blocks Western dietinduced gene expression of the chemokines CXCL10 and CCL2 in the prefrontal cortex. Brain, behavior, and immunity 2016; 58: 82-90. 